Review Article

\title{
Lysosomal diseases: Overview on current diagnosis and treatment
}

Fabiano de Oliveira Poswar ${ }^{1,3^{*}}$, Filippo Vairo ${ }^{4,5^{*}}$ iD, Maira Burin ${ }^{1}$, Kristiane Michelin-Tirelli ${ }^{1}$, Ana Carolina Brusius-Facchin ${ }^{1}$, Francyne Kubaski ${ }^{1}$ (iD, Carolina Fischinger Moura de Souza ${ }^{1}$, Guilherme Baldo ${ }^{1,6,7}$ iD and Roberto Giugliani ${ }^{1,2,3}$ iD

${ }^{1}$ Medical Genetics Service, Hospital de Clínicas de Porto Alegre, Porto Alegre, RS, Brazil.

${ }^{2}$ Department of Genetics, Universidade Federal do Rio Grande do Sul, Porto Alegre, RS, Brazil.

${ }^{3}$ Postgraduate Program in Genetics and Molecular Biology, Universidade Federal do Rio Grande do Sul, Porto Alegre, RS, Brazil.

${ }^{4}$ Center for Individualized Medicine, Mayo Clinic, Rochester, MN, USA.

${ }^{5}$ Department of Clinical Genomics, Mayo Clinic, Rochester, MN, USA.

${ }^{6}$ Postgraduate Program in Physiology, Universidade Federal do Rio Grande do Sul, Porto Alegre, RS,

Brazil.

${ }^{7}$ Department of Physiology and Pharmacology, Universidade Federal do Rio Grande do Sul, Porto Alegre, RS, Brazil.

\begin{abstract}
Lysosomal diseases (LDs), also known as lysosomal storage diseases (LSDs), are a heterogeneous group of conditions caused by defects in lysosomal function. LDs may result from deficiency of lysosomal hydrolases, membrane-associated transporters or other non-enzymatic proteins. Interest in the LD field is growing each year, as more conditions are, or will soon be treatable. In this article, we review the diagnosis of LDs, from clinical suspicion and screening tests to the identification of enzyme or protein deficiencies and molecular genetic diagnosis. We also cover the treatment approaches that are currently available or in development, including hematopoietic stem cell transplantation, enzyme replacement therapy, small molecules, and gene therapy.
\end{abstract}

Keywords: Lysosomal storage diseases, neonatal screening, hematopoietic stem cell transplantation, enzyme replacement therapy, gene therapy.

Received: June 15, 2018; Accepted: October 30, 2018.

\section{Introduction}

Lysosomes are membrane-bound organelles, which contain, among other components, hydrolytic enzymes that operate in an acidic environment (Sabatini and Adesnik, 2014). Lysosomes are capable of digesting all types of macromolecules and participate in the breakdown of both extracellular and intracellular components that are targeted to them through the processes of endocytosis or autophagy, respectively.

Lysosomal diseases, also known as lysosomal storage diseases, are a heterogeneous group of diseases caused by defects in lysosomal function (Valle et al., 2014). Most LDs result from a deficiency in lysosomal hydrolases (e.g., alpha-galactosidase in Fabry disease). Alternatively, LDs may be caused by deficiencies in lysosomal membrane-

Send correspondence to Filippo Vairo. Center for Individualized Medicine and Department of Clinical Genomics, Mayo Clinic, Rochester, MN, USA. 200 First Street SW, 55905 Rochester, MN, USA.

E-mail: vairo.filippo@mayo.edu

*These authors contributed equally to this work. associated transporters (e.g., cystinosin in cystinosis) or other non-enzymatic proteins (e.g., CLN3 in Batten disease). According to the WORLDSymposia ${ }^{\circledR}$ official list of lysosomal diseases, 66 clinical conditions related to 53 distinct genes are recognized as LDs (WORLDSymposium, 2018).

Although individually very rare, the incidence of LDs as a group is estimated to be as high as 1 in 4000 in some countries (Giugliani et al., 2017a). The exact prevalence is difficult to estimate, considering the clinical heterogeneity of LDs, which may lead to missed diagnoses. According to Medical Genetics Service of the Hospital de Clínicas de Porto Alegre data, the investigation of high-risk subjects led to 3,512 LD diagnoses in Brazil from 1982 to 2017 (Table 1).

Interest in the LD field is growing as more conditions are now treatable or are expected to be treatable in the near future by distinct approaches including hematopoietic stem cell transplantation, enzyme replacement, small molecules, and gene therapy (Beck, 2018). Research in this field is also 
Table 1 - Lysosomal storage diseases diagnosed from 1982 to 2017 by the Reference Laboratory of Inborn Errors of Metabolism, Medical Genetics Service, Hospital de Clinicas de Porto Alegre, Brazil.

\begin{tabular}{|c|c|}
\hline Lysosomal storage disease & $\begin{array}{c}\text { Number of confirmed } \\
\text { diagnoses }\end{array}$ \\
\hline \multicolumn{2}{|l|}{ Mucopolysaccharidoses } \\
\hline Mucopolysaccharidosis type I & 262 \\
\hline Mucopolysaccharidosis type II & 413 \\
\hline Mucopolysaccharidosis type IIIA & 67 \\
\hline Mucopolysaccharidosis type IIIB & 104 \\
\hline Mucopolysaccharidosis type IIIC & 68 \\
\hline Mucopolysaccharidosis type IVA & 193 \\
\hline Mucopolysaccharidosis type IVB & 13 \\
\hline Mucopolysaccharidosis type VI & 281 \\
\hline Mucopolysaccharidosis type VII & 22 \\
\hline Multiple sulfatase deficiency & 9 \\
\hline \multicolumn{2}{|l|}{ Glycoproteinoses } \\
\hline Aspartylglucosaminuria & 1 \\
\hline Fucosidosis & 4 \\
\hline Galactosialidosis & 19 \\
\hline$\alpha$-Mannosidosis & 9 \\
\hline Mucolipidosis II/III & 41 \\
\hline Sialidosis & 14 \\
\hline \multicolumn{2}{|l|}{ Sphingolipidoses } \\
\hline Fabry disease & 109 \\
\hline Gaucher disease & 756 \\
\hline GM1 gangliosidosis & 181 \\
\hline GM2 Tay-Sachs disease (44\% B1) & 144 \\
\hline GM2 Sandhoff disease & 30 \\
\hline Krabbe disease & 109 \\
\hline Metachromatic leukodystrophy & 164 \\
\hline Niemann-Pick type A/B disease & 225 \\
\hline \multicolumn{2}{|l|}{ Other LDs } \\
\hline Lysosomal acid lipase deficiency & 11 \\
\hline Neuronal ceroid lipofuscinosis 1 (CLN1) & 6 \\
\hline Neuronal ceroid lipofuscinosis 2 (CLN2) & 43 \\
\hline Niemann-Pick type C & 161 \\
\hline Pompe disease & 52 \\
\hline Salla disease & 1 \\
\hline TOTAL & 3512 \\
\hline
\end{tabular}

* Classified as proposed by Kingma et al., 2015.

important, as molecular pathways related to lysosomal disease pathophysiology are increasingly recognized as being impaired in more common conditions including Parkinson's disease and aging (Lloyd-Evans and Haslett, 2016).

\section{Clinical suspicion}

LD symptomatology depends on the stored substrate and organs affected by this accumulation. Usually, sub- strate accumulation occurs in the organs where they are synthesized (e.g., liver, spleen, bone, etc.), which partially explains the involvement of different organs. Issues with the targeting of enzymes to lysosomes, defective membrane proteins, and abnormal excretion of substrates may also cause lysosome enlargement and functional impairment. Thus, the wide range of symptoms in LD may be explained by the activation of several deleterious processes, such as the release of acid hydrolases into the cytoplasm causing cellular damage, the dysregulation of apoptosis or the abnormal accumulation of lipids causing defective transport of substrates into and out of the lysosomes.

LDs are traditionally classified according to the substance that accumulates abnormally. However, this classification is merely for convenience, since there is overlap in the substrate specificities of enzymes. The major categories of LDs are mucopolysaccharidoses, mucolipidoses, sphingolipidoses, oligosaccharidosis, and neuronal ceroid lipofuscinoses (Giugliani et al., 2017b).

There are some phenotypic features that should raise the suspicion of LD. For example, if a patient presents with coarse facial features, hepatosplenomegaly, and skeletal abnormalities, one should suspect mucopolysaccharidosis, mucolipidosis, or oligosaccharidosis, remembering that there are subtypes associated with neurological impairment or corneal clouding, which could lead to a more precise diagnosis. A very specific sign, such as a "cherry red" spot in the retina, indicates that the physician should prioritize GM1- and GM2-gangliosidosis as a possible differential diagnosis. Angiokeratomas are almost specific for Fabry disease and fucosidosis, for instance. A patient with anemia, thrombocytopenia, and hepatosplenomegaly should be evaluated for Gaucher and Niemann-Pick type B diseases. For any patient presenting with neurodegeneration and vision issues at any age, the clinical team should suspect an underlying neuronal ceroid lipofuscinosis. For three out of the 14 neuronal ceroid lipofuscinosis types there is an enzymatic test clinically available. For the other types, genetic analysis or electron microscopy of lymphocytes or fibroblasts is advised.

Examples of diseases within each of the categories and the major signs and symptoms seen in patients with diseases in each group are summarized in Table 2.

\section{Considerations regarding the diagnosis of LDs}

\section{Biomarkers and screening tests}

In the LDs associated with enzyme deficiencies, diagnosis is usually performed by the direct measurement of the activity of the enzyme associated with the disease. To identify which enzyme assay should be performed, it is useful to measure biomarkers, indicated by the clinical picture. Biomarkers may be especially important when the LD is caused by the deficiency of a non-enzymatic protein, which could be difficult to measure. 
Table 2 - Major signs and symptoms of LDs.

\begin{tabular}{|c|c|c|}
\hline Major LD category & Examples & Major signs and symptoms* \\
\hline Mucopolysaccharidoses & $\begin{array}{l}\text { MPS I (IH, IS, and IH/S); MPS II; MPS III } \\
\text { (A, B, C, and D); MPS IV (A and B); MPS VI; MPS } \\
\text { VII, MPS IX }\end{array}$ & $\begin{array}{l}\text { Coarse facial features, hepatosplenomegaly, corneal cloud- } \\
\text { ing, skeletal abnormalities, joint limitation, and short stat- } \\
\text { ure; progressive mental retardation occurs in some types }\end{array}$ \\
\hline Mucolipidoses & Type I; Type II; Type III; Type IV & $\begin{array}{l}\text { Coarse facial features, hepatosplenomegaly, dysostosis mul- } \\
\text { tiplex, finger contractures, scoliosis, short stature; progres- } \\
\text { sive mental retardation occurs in some types }\end{array}$ \\
\hline Sphingolipidoses & $\begin{array}{l}\text { GM2-gangliosidoses; Niemann-Pick (types } \\
\text { A, B, and C); Gaucher disease (types I, II, and III); } \\
\text { Fabry disease; Metachromatic leukodystrophy; } \\
\text { Krabbe disease; Farber lipogranulomatosis }\end{array}$ & $\begin{array}{l}\text { Neurodegeneration, "cherry red" spot in the ret- } \\
\text { ina, hepatosplenomegaly, pulmonary involvement, gaze } \\
\text { palsy, ataxia, bone } \\
\text { changes, paresthesias, angiokeratomas, renal failure }\end{array}$ \\
\hline Oligosaccharidoses & $\begin{array}{l}\alpha \text {-mannosidosis; } \beta \text {-mannosidosis; fucosidosis; } \\
\text { aspartylglucosaminuria; Schindler disease; ISSD; } \\
\text { Salla disease; Galactosialidosis; GM1-gangliosidosis }\end{array}$ & $\begin{array}{l}\text { Coarse facial features, dysostosis multiplex; "cherry red" } \\
\text { spot in the retina, hepatosplenomegaly, mental retarda- } \\
\text { tion, ataxia, hearing loss, angiokeratoma }\end{array}$ \\
\hline
\end{tabular}

IH: Hurler; IS: Sheie; IH/S: Hurler-Scheie; ISSD: Infantile sialic acid storage disease.

*May not be present in all diseases in the same category.

The measurement of biomarkers in different biological samples (blood, urine, cerebrospinal fluid) can be carried out either before or simultaneously with the enzyme activity measurement. A biomarker is generally an analyte that indicates the presence and/or extent of a biological process, which is in itself usually directly linked to the clinical manifestations and outcome of a particular disease (Bobillo Lobato et al., 2016). To assess the effectiveness of therapies, it is helpful to use biomarkers that allow us to analyze the evolution of the disease over time, determining how the accumulation of products diminishes. Biomarkers are a key component not only of the diagnosis, but also for monitoring patients and for choosing the best therapeutic option in each case. Biomarkers are also important in the case of pseudo-deficiencies, as they can provide information about the functional consequences of the detected enzyme abnormality.

Biomarkers may be analyzed qualitatively or quantitatively. Qualitative analyses (thin-layer chromatography, electrophoresis, spot tests, etc.), allow the identification of biomarkers but with low sensitivity and specificity. For instance, thin-layer chromatography of oligosaccharides is generally used but should soon be replaced by quantitative methods (Raymond and Rinaldo, 2013). For quantitative analyses, it is possible to use colorimetric methods, but tandem mass spectrometric methods seem to be most promising (Blau et al., 2008).

For Fabry disease (FD), the analysis of globotriaosylsphingosine (lyso-Gb3) is preferable to globotriaosylceramide $(\mathrm{Gb}-3)$, because there is not a clear correlation between $\mathrm{Gb} 3$ levels and the clinical manifestation or severity of the disease. DBS provides a convenient, sensitive, and reproducible source to measure lyso-Gb3 levels for diagnosis, initial phenotypic assignment, and therapeutic monitoring in patients with FD (Nowak et al., 2017a). Furthermore, it has been proven that lyso-Gb3 in plasma is a useful biomarker for the diagnosis and treatment of FD het- erozygotes (Nowak et al., 2017b). Proteinuria and creatinine are practical biomarkers of renal damage. Troponin I and high-sensitivity assays for cardiac troponin $\mathrm{T}$ can identify patients with cardiac lesions, but new cardiac imaging techniques are necessary to detect incipient damage (Beirão et al., 2017).

The classical biomarker for Gaucher disease (GD) is chitotriosidase (ChT). ChT activity has been shown to correlate well with various clinical parameters and has been used to monitor and adjust the treatment, despite being not specific for GD. It should be mentioned that there are a significant number of individuals in the general population $(\sim 1: 20)$ with low chitotriosidase activity due to a common polymorphism. One alternative option for these cases is the pulmonary and activation-regulated chemokine (CCL18/PARC) (Bobillo Lobato et al., 2016). Another biomarker for GD is glucosylsphingosine, (proposed by Rolfs et al., 2013), which is considered more specific than chitotriosidase or CCL18. Measured with LC-MS/MS, glucosylsphingosine achieved $100 \%$ specificity in identifying Gaucher patients (Rolfs et al., 2013). The plasma biomarkers macrophage inflammatory protein 1-alpha and 1-beta (MIP-1 $\alpha$ and MIP-1 $\beta$ ) (van Breemen et al., 2007), and cathepsin $\mathrm{K}$ have been used to study bone disease. Another alternative to chitotriosidase is osteopontin, which seems to have great potential as a biomarker for GD, although further investigation is still necessary (Vairo et al., 2015).

Psychosine (PSY, galactosylsphingosine) has been suggested as a biomarker for the presence and progression of Krabbe disease (KD). PSY can be analyzed in blood, DBS, and cerebrospinal fluid. The psychosine concentration in patients with the infantile form of $\mathrm{KD}$ is at least four-fold higher than in asymptomatic newborns with low galactosylcerebrosidase activity, and nearly one order of magnitude greater than in healthy newborns (Bobillo Lo- 
bato et al., 2016). PSY measurement in DBS could serve as a second tier assay in newborn screening for $\mathrm{KD}$, simplifying and reducing the cost of follow-up protocols (Turgeon et al., 2010). Quantitative analysis of diffusion tensor imaging (DTI) scalars, especially radial diffusivity and fractional anisotropy, has been shown to be a sensitive in vivo biomarker of white matter microstructural damage in $\mathrm{KD}$ (Poretti et al., 2016).

For mucopolysaccharidoses (MPS), the investigation can start with urinary screening tests. Glycosaminoglycans (GAGs) are the most common and widely used biomarkers for MPS and several qualitative and quantitative methods have been used to-date (alcian blue, toluidine blue, paper and thin layer chromatography, gas chromatography, high-pressure liquid chromatography, capillary electrophoresis, 1,9-dimethylmethylene blue, carbazol, enzymelinked immunosorbent assay, mass spectrometry, and others). Sensitivity and specificity of the dye-spectrometric and TLC methods are not sufficient to detect all types of MPS, especially MPS III and MPS IV (Kubaski et al., 2017). Many studies have reported the analysis of glycosaminoglycan fragments by tandem mass spectrometry as a potential biomarker for MPS. Recently, a new quantitative UPLC-MS/MS method for heparin sulfate (HS), dermatan sulfate (DS), and chondroitin sulfate (CS) has taken advantage of equipment that is available at some clinical laboratories with basic triple quadrupole MS/MS systems. This method allows the determination of urinary levels of these biomarkers and facilitates diagnosis for patients with MPS I, II, III, IVA, and VI, as well as other lysosomal storage disorders. Langereis et al. (2015) adapted GAG quantification protocols by adding KS to provide a multiplex assay not only for the diagnosis of MPS but also for Mucolipidoses II and III.

Other MPS biomarkers in urine were identified using proteomics: $\beta$-galactosidase, collagen type I, fatty acidbinding protein 5 , nidogen- 1 , cartilage oligomeric matrix protein, insulin-like growth factor binding protein 7 , and Heg1. These compounds demonstrate a relationship between biomarker concentrations and disease severity (Bobillo Lobato et al., 2016).

Sphingomyelin is elevated in Niemann-Pick diseases [both acid sphingomyelinase deficiency (ASMD, NP-A, NP-B) and Niemann-Pick C (NP-C)], but is not a reliable biomarker due to the overlap between the levels observed in patients and healthy controls. Lysosphingomyelin (lyso-SPM) levels in DBS seem to be a good alternative to sphyngomyelin. However, in patients with ASMD deficiency, lyso-SPM concentration does not correlate with the amount of residual enzyme activity in DBS or with patient age. The analysis of chitotriosidase or filipin staining of free cholesterol in fibroblasts lacks sensitivity and specificity for NP-C detection (Bobillo Lobato et al., 2016). Recently, two metabolites that are markedly increased in NP-C patients have been identified as biomarkers. Higher levels of cholestane-3 $3,5 \alpha, 6 \beta$-triol (C-triol) and 7-ketocholesterol (7-KC) are present in the plasma of NP-C patients when compared to plasma from patients with other LDs or control subjects. The concentration of these biomarkers correlates directly with the disease state, and they are specific to NP-C (Hammerschmidt et al., 2018). Additional biomarkers have been described including 24(S)hydroxycholesterol, which is reduced in the plasma and cerebrospinal fluid (CSF) (Tortelli et al., 2014), bile acids in plasma, DBS, and urine; calbindin D, a compound found in cerebrospinal fluid (Bradbury et al., 2016), and lysosphingomyelin-509 in plasma (Giese et al., 2015).

Tetrasaccharide glucose (Glc4) is the most wellknown biomarker for Pompe disease (PD) but is not specific, and its use for diagnostic purposes may be limited (Young et al., 2009). The most frequently used technique is high-performance liquid chromatography with ultraviolet detection (HPLC/UV) due to its efficiency and availability in laboratories. There is a good correlation between urinary excretion of Glc4 and response to therapy (Manwaring et al., 2012). Two other serum biomarkers, myostatin and insulin-like growth factor I (IGF-I), can be used for Pompe diesase, and increase after treatment (Bobillo Lobato et al., 2016).

\section{Identification of the enzyme or protein deficiencies}

Enzymes are proteins that catalyze chemical reactions and have high specificity for their substrates. This specificity allows the enzymes to be used to quantify their substrates. Additionally, the substrates can be used to determine the amount of enzyme present in a biological sample. Substrate binding occurs at the "active site" (Figure 1). The reaction rate will become maximal when the active sites of the enzyme molecules are occupied. Important variables to determine the enzymatic activity include temperature, $\mathrm{pH}$, substrate concentration, cofactors, and the use of direct or indirect reactions to quantify the enzyme (Nelson et al., 2014).

There are two important ways to determine the amount of enzyme in biological fluids. Most commonly, enzymes are quantified by determining their enzymatic activity by measuring the rate of a reaction catalyzed by the enzyme. In enzyme activity assays, some methods use endpoint quantification, determining the concentration of the substrate or product at a specific time after the addition of the sample. The biological fluids used for the enzymatic investigation of LDs include plasma, serum, leukocytes, cultured fibroblasts, dried blood spots (DBS), chorionic villi, amniotic fluid, and cultured amniocytes, among others (Henry and Gubert, 2008).

Most enzymatic assays for LD research rely on spectrofluorometry, which uses enzyme-specific substrates with a fluorogenic radical to generate a fluorophore product that will absorb energy at a specific wavelength and then emit it at another longer wavelength to determine the quan- 


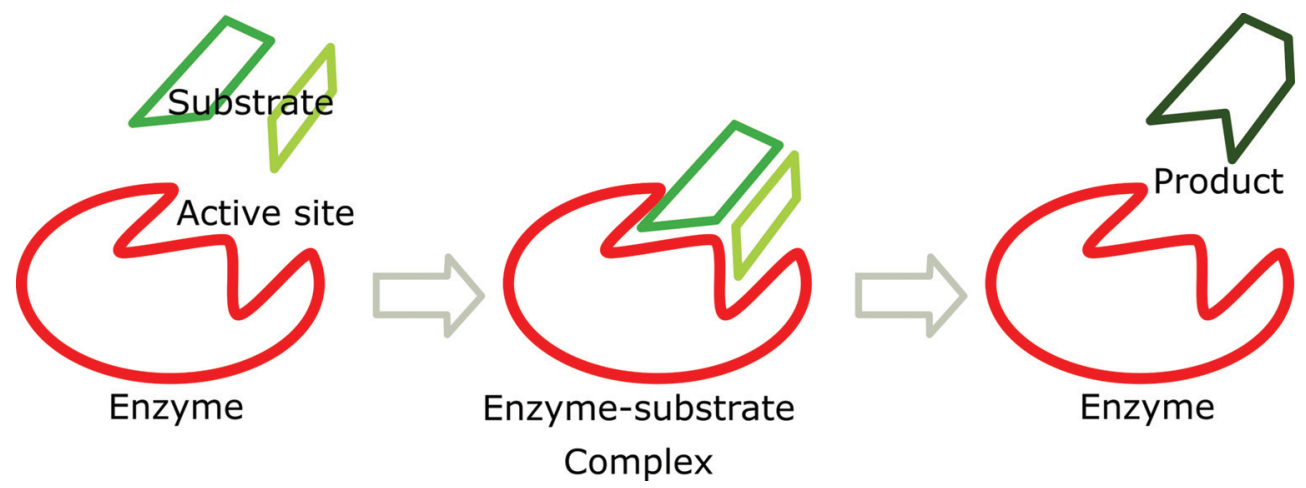

Figure 1 - Hypothetical scheme of an enzymatic reaction. Point mutations in the gene encoding an enzyme may alter its enzymatic activity leading to substrate accumulation and a lack of product. In addition, it may also cause the accumulated substrate to follow an alternative route. This is the cause of many LDs.

tity of product produced. Spectrophotometry is also a widely used technique based on chromophores that excite themselves and emit colors depending on the energy released by the change from the basal to the excited state (Burns, 2016).

\section{Molecular genetic diagnosis}

Precise molecular diagnosis (MD) is of great importance for LDs, not only to confirm the enzymatic diagnosis but also to ascertain a definitive diagnosis in complex situations.

Classification of disease severity based on the molecular defects may be useful when the enzyme deficiency and clinical information do not allow for a clear distinction between severe and more attenuated forms, and in cases where the specific enzyme shows high residual activity in affected patients and low enzymatic activity in unaffected patients (pseudodeficiencies). Moreover, MD is useful for those showing multiple enzyme deficiencies (e.g., multiple sulfatase deficiency and mucolipidoses II and III,), and for confirmation of the diagnosis in X-linked conditions where the specific enzyme deficiency is not informative (females with FD), due to the overlap of the enzyme activities with the normal controls range. In addition, MD is essential for confirmation of the diagnosis in cases where the functional defect does not involve an enzyme deficiency (e.g., neuronal ceroid lipofuscinosis and Niemann-Pick C disease) (Filocamo and Morrone, 2011).

MD can be made using DNA or RNA and utilizes a range of different molecular approaches, such as Sanger sequencing, restriction fragment length polymorphism (RFLP) analysis, amplification-refractory mutation system (ARMS), multiplex ligation-dependent probe amplification (MLPA), real-time PCR, and high-resolution melting. Currently, massive parallel sequencing technology, also known as next-generation sequencing (NGS), allows for the sequencing of large genomic regions in a short time period at relatively low cost, replacing the traditional analysis of individual genes and exon-by-exon sequencing. NGS applications include the sequencing of PCR-amplified ge- nomic regions, whole-exome sequencing (WES), and whole-genome sequencing (WGS).

DNA sequencing is the primary clinical technique to identify mutations in LDs, but sequencing often does not detect intragenic or whole-gene deletions/duplications. Therefore, comparative genomic hybridization (CGH) using oligonucleotide arrays has been implemented in cytogenetic and molecular diagnostic laboratories as a robust, rapid, and sensitive assay for detecting targeted gene deletions (Brusius-Facchin et al., 2014).

Since there are many lysosomal disorders that do not result from lysosomal enzyme deficiencies detected by clinically available tests, molecular testing must be considered as an important tool for the diagnosis of LDs. In this sense, WES has been reported as an important approach to diagnose LDs with unspecific phenotypes (Vairo et al., 2017). Moreover, the determination of the genotype can be helpful in prenatal diagnosis, carrier detection, and for therapy options choice.

\section{Neonatal screening}

Many studies suggest that it is feasible to screen for up to 10 LDs by measuring lysosomal enzymatic activities in DBS. DNA sequencing is not currently a first-tier option for newborn screening (NBS), although it has been considered as a complementary approach in some cases. The use of biomarkers is also not moving forward as a first-tier option for NBS of LDs, either because the analysis time per sample is too long for high-throughput NBS, or due to the high false-positive rates (3-5\% in some reports). However, these methods are expected to be extremely valuable for second-tier analyses (in positive cases identified by enzyme activity assay), especially when the same DBS can be used, which would avoid patient recall and parental anxiety. As an example, for metachromatic leukodystrophy, the most promising approach for NBS is the analysis of sulfatides in DBS by MS/MS, since arylsulfatase A cannot be measured in DBS and its pseudodeficiency is quite common (Schielen et al., 2017). As pilot studies have been completed worldwide and knowledge on the prevalence of 
these diseases increases, several national (or regional) screening programs have been adding LDs to their testing portfolio. In Taiwan, Pompe, Fabry, Gaucher, MPS-I, MPS-II, MPS-IVA, and MPS-VI are included in the national screening program. Some states in US, such as New York, Ohio, and Kentucky have included LDs to the NBS programs, and others are about to start screening for them. In Europe, only a few countries have started screening for LDs (Schielen et al., 2017). A major concern about screening for these disorders is the presence of pseudodeficiencies that can cause a burden to the families and health systems. Another important matter is how to follow-up and/or treat the patients predicted to have late-onset forms. All these issues should be taken into account when discussing the screening for LDs.

\section{Considerations about treatment}

\section{Hematopoietic stem cell transplantation}

Hematopoietic stem cell transplantation (HSCT) is a known treatment for LDs due to the remarkable properties of self-renewing enzyme-producing cells to secrete the deficient enzyme and colonize enzyme-deficient tissues, allowing constant intercellular enzyme exchange. In this cross-correction process, secreted enzymes can be taken up from the reticuloendothelial system by deficient cells via the mannose-6-phosphate (M6P) or mannose receptors and transported to lysosomes where substrates can be properly degraded (Neufeld and Fratantoni, 1970; Kornfeld, 1992; Lund, 2013; Macauley, 2016; Mikulka and Sands, 2016; Jiang et al., 2017). The main sources for HSCT are bone marrow (BM), peripheral stem cells (PSC), and cord blood (CB) (Aldenhoven et al., 2015; Jiang et al., 2017).

HSCT is considered a standard of care treatment for MPS type I, and it has been suggested for the treatment of metachromatic leukodystrophy (Boucher et al., 2015; Boelens and van Hasselt 2016; Lum et al., 2017; Parini et al., 2017). Several reports have also indicated variable benefits of HSCT for MPS II (Barth et al., 2017; Kubaski et al., 2017), MPS VI (Behfar et al., 2017), MPS IVA (Chinen et al., 2014; Yabe et al., 2016), MPS VII (Yamada et al., 1998; Montaño et al., 2016), Krabbe disease (Langan et al., 2016; Maher and Yeager, 2016; Mikulka and Sands, 2016; Wright et al., 2017), and fucosidosis (Jiang et al., 2017).

HSCT is not a curative treatment for most LDs. However, it can slow disease progression and improve survival rates and quality of life for several of these disorders. The most crucial factor for improved outcomes is for the transplant to be performed as early as possible, ideally while patients are still asymptomatic. Newborn screening will greatly improve early detection of patients, allowing early transplantation that could be performed ideally before two weeks of age (Wright et al., 2017) (Figure 2). For the first time, Barth et al. (2017) have recently demonstrated good

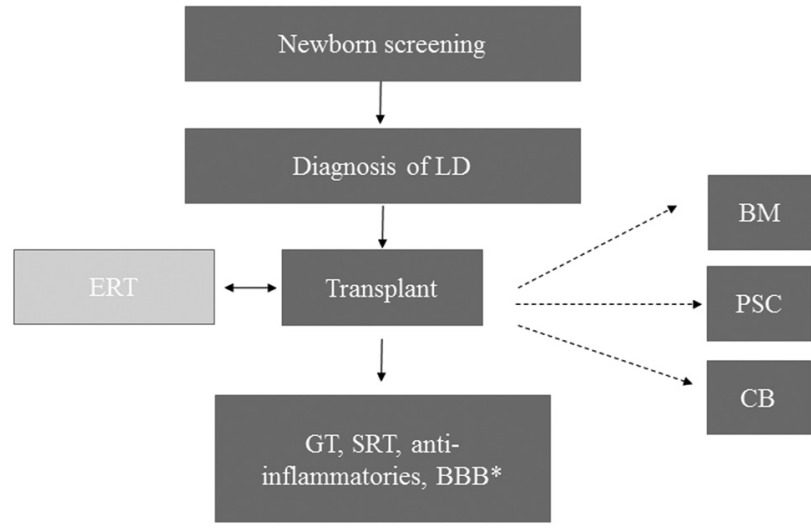

Figure 2 - Tentative workflow for HSCT combined with newborn screening. After diagnosis of LDs, patients can receive a transplant as early as two weeks of age. ERT may start prior to the transplant and can be continued for the first few months until full chimerism is achieved. HSCT can also be combined with gene therapy, substrate reduction therapy, antiinflammatories, and molecules that increase blood-brain barrier permeability to improve clinical outcomes. LD: lysosomal disorder; ERT: enzyme replacement therapy; BM: bone marrow; PSC: peripheral stem cell; CB: cord blood; GT: gene therapy; SRT: substrate reduction therapy; BBB: blood brain barrier; $\mathrm{BBB}^{*}$ : molecules that increase BBB permeability.

HSCT outcomes in an MPS II patient transplanted at 70 days of age.

An advantage of HSCT over enzyme replacement therapy (ERT) is the fact that donor cells can cross the blood-brain barrier (BBB) and thus improve neurological impairment. However, CNS repopulation is a very slow process, which usually takes several months to occur, thus justifying the need for early HSCT to improve CNS impairment (Maher and Yeager, 2016). Finally, it should be mentioned that HSCT could potentially be combined with ERT, gene therapy (GT), substrate reduction therapy, and molecules that increase BBB permeability in order to improve clinical outcomes (Mikulka and Sands, 2016; Macauley, 2016).

\section{Enzyme replacement therapy}

Lysosomes are cytoplasmic organelles that contain a variety of hydrolases. A genetic deficiency in the enzymatic activity of one of these hydrolases will lead to the accumulation of the material meant for lysosomal degradation (Ferreira and Gahl, 2017).

ERT was first successfully administered to humans with LDs over 25 years ago and was the first therapy that directly addressed the underlying mechanism causing a genetic disease. ERT is based on the intravenous infusion of a recombinant enzyme (similar to the natural one), which is taken up into the cell through membrane receptors (typically mannose-6-phosphate receptors) and replaces the catalytic action of the missing or non-functional lysosomal enzyme (Ortolano et al., 2014). A functional version of the missing or hypoactive enzyme is produced by genetically engineered cell lines in a cGMP-compliant fashion. The purified enzyme may sometimes be modified to better target 
the lysosomal targeting pathways (Rastall and Amalfitano, 2017).

GD was the first LD for which the recombinant human $\beta$-glucocerebrosidase enzyme was developed and approved by the FDA in 1991 (Barton et al., 1991). Development of ERT for FD followed (Biegstraaten et al., 2015). ERT has also been developed for PD, MPS types I, II, IVA, VI, and VII, and lysosomal acid lipase deficiency, becoming the mainstay of treatment for individuals affected by these disorders (Rastall and Amalfitano, 2017). ERT has been the most successful treatment for LDs todate and is currently being explored for other conditions such as acid sphingomyelinase deficiency (Wasserstein et al., 2018) and alpha-mannosidosis (Borgwardt et al., 2013). Table 3 shows a list of LDs and different forms of ERT.

ERT represents a major advancement in the treatment of genetic disorders. However, the development and implementation of large-scale ERTs has unmasked several challenges in the treatment of LDs (Rastall and Amalfitano, 2017). Recombinant enzymes are very expensive and not all patients may benefit from them. Due to intravenous ERT not being efficacious in controlling CNS disease manifestations, the BBB limitation has been addressed with different routes of administration, including intracerebroventricular (ICV) and intrathecal (IT) delivery. The ICV approach has been approved for neuronal ceroid lipofuscinosis II (CLN2), and trials are ongoing to prove its safety and efficacy in several other conditions (Ortolano et al., 2014). IT ERT was first used in a MPS patient in Brazil (MunozRojas et al., 2008) and is currently in clinical trials for MPS I (IT), MPS II (IT and ICV), and MPS IIIB (ICV) (Dickson et al., 2015; Muenzer et al., 2016; Muschol et al., 2018).
A promising strategy to enable enzymes to penetrate the blood-brain barrier is the development of fusion proteins, in which enzyme molecules are attached to peptides or peptidomimetic antibodies that can cross this barrier through receptor-mediated endocytosis and act as so-called molecular "Trojan horses." One such approach includes the use of a human insulin receptor monoclonal antibody, which has been tested in rhesus monkeys and is able to deliver sufficient amounts of $\alpha$-iduronidase, iduronate-2-sulphatase, sulphamidase, and $\alpha-N$-acetylglucosaminidase to the CNS (Pardridge et al., 2018).

It is important to note that ERT requires lifelong, repeated infusions of large quantities of the respective exogenous enzyme. The amounts of enzyme that must be infused to effectively treat all affected cells, tissues, or organs in an LD patient can be quite large, and producing this much enzyme using current-GMP-compliant production methods can be very expensive and is likely limiting. Furthermore, ERT relies on active transport to eventually enter the cell and then the lysosome. These are likely rate-limiting steps; thus, despite massive infusions of recombinant enzyme, only a small proportion may actually make it into the lysosome (Jurecka and Tylki-Szymanska, 2015). Finally, due to individual genetic backgrounds, ERT can potentially elicit an immune response against the recombinant enzyme itself with higher titers correlating with poorer responses to the therapy (van Gelder et al., 2015).

\section{Small molecule therapy}

Small molecules are a more-recent development in the field of specific treatments for LDs. Instead of replacing a deficient enzyme, as in ERT, small molecules address the underlying mechanisms of the LDs by different methods including the reduction of the amount of substrate and the

Table 3 - Approved enzyme replacement therapies.

\begin{tabular}{|c|c|c|c|c|}
\hline Disease & Generic name & Brand name & Dose & Delivery \\
\hline \multirow[t]{3}{*}{ Gaucher type I } & Imiglucerase & Cerezyme ${ }^{\circledR}$ & 60 Units/kg (every other week) & I.V. infusion \\
\hline & Taliglucerase alfa & Elelyso ${ }^{\circledR}$ & 60 Units/kg (every other week) & \\
\hline & Velaglucerase alfa & Vpriv ${ }^{\circledR}$ & 60 Units/kg (every other week) & \\
\hline \multirow[t]{2}{*}{ Fabry disease } & Agalsidase beta & Fabrazyme® & $1 \mathrm{mg} / \mathrm{kg}$ (every other week) & I.V. infusion \\
\hline & Agalsidase alfa & Replagal ${ }^{\circledR}$ & $0.2 \mathrm{mg} / \mathrm{kg}$ (every other week) & \\
\hline \multirow[t]{2}{*}{ Pompe disease } & Alglucosidase alfa & Myozyme ${ }^{\circledR}$ & $20 \mathrm{mg} / \mathrm{kg}$ (every other week) & I.V. infusion \\
\hline & Alglucosidase alfa & Lumizyme ${ }^{\circledR}$ & & \\
\hline MPS I - Hurler, Hurler-Scheie and Scheie & Laronidase & Aldurazyme ${ }^{\circledR}$ & $0.58 \mathrm{mg} / \mathrm{kg}$ (once per week) & I.V. infusion \\
\hline MPS II - Hunter Syndrome & Idursulfase & Elaprase ${ }^{\circledR}$ & $0.5 \mathrm{mg} / \mathrm{kg}$ (once per week) & I.V. infusion \\
\hline MPS VI - Maroteaux-lamy syndrome & Galsulfase & Naglazyme ${ }^{\circledR}$ & $1 \mathrm{mg} / \mathrm{kg}$ (once per week) & I.V. infusion \\
\hline MPS IVA - Morquio A syndrome & Elosulfase alfa & Vimizim ${ }^{\circledR}$ & $2 \mathrm{mg} / \mathrm{kg}$ (once per week) & I.V. infusion \\
\hline Lysosomal acid lipase deficiency & Sebelipase alfa & Kanuma ${ }^{\circledR}$ & $1 \mathrm{mg} / \mathrm{kg}$ (every other week) & I.V. infusion \\
\hline $\begin{array}{l}\text { Late infantile neuronal ceroid } \\
\text { lipofuscinosis type } 2 \text { (CLN2) }\end{array}$ & Cerliponase alfa & Brineura ${ }^{\circledR}$ & $300 \mathrm{mg}$ (every other week) & Intraventricular \\
\hline MPS VII - Sly syndrome & Vestronidase alfa & Mepsevii® & $4 \mathrm{mg} / \mathrm{kg}$ (every other week) & I.V. infusion \\
\hline
\end{tabular}


stabilization of the endogenous enzyme as a pharmacological chaperone. These therapies may have important advantages, including the possibility of being administered orally, the ability to cross the blood-brain barrier, a lack of hypersensitivity reactions, and lower manufacturing costs. Table 4 summarizes the small molecules currently approved for the treatment of LDs.

In many LDs, symptoms are caused by the accumulation of a substrate, rather than the lack of an enzymatic product, thus having the potential to be treated by downregulating the biosynthesis of the substrate (Coutinho et al., 2016). In GD, two distinct compounds (miglustat and eliglustat), which function as glucosylceramide synthase inhibitors have been shown to have beneficial effects. Miglustat is approved for the treatment of patients with type I GD who are unable to receive ERT. Eliglustat is licensed as a first-line treatment for adult patients with type I GD (Balwani et al., 2016; Belmatoug et al., 2017). There is currently no consensus on whether they have the same efficacy as ERT (Zimran et al., 2018). Nevertheless, the suc- cessful application of substrate reduction therapy (SRT) in the treatment of GD has encouraged the development of new small molecules or RNA-degrading technologies to achieve substrate reduction in GD and other diseases, including PD, KD, and MPS (Cabrera-Salazar et al., 2012; Coutinho et al., 2016; Sands and LeVine, 2016; Derrick-Roberts et al., 2017; Kishnani et al., 2017).

In non-enzymatic LDs, small molecules may be the only available treatment. In Niemann-Pick type $\mathrm{C}$ disease, in which the primary defect is in the intracellular cholesterol trafficking proteins NPC1 and NPC2, miglustat has been shown to reduce glycolipid storage in the neurons of patients. Thus, leading to improvement in horizontal saccadic eye movements, velocity and stabilization of ambulation, manipulation, language and swallowing scores (Lyseng-Williamson, 2014; Bowman et al., 2017). Cysteamine, used in the therapy of nephropathic cystinosis, is the only specific treatment of this condition and is one of the first-approved LD treatments (Ariceta et al., 2017). Cysteamine breaks cysteine into cysteine and cysteine-

Table 4 - Approved small molecule-based therapies for lysosomal diseases.

\begin{tabular}{|c|c|c|c|c|}
\hline Disease & Compound & Class & Safety & Efficacy evidence \\
\hline \multirow[t]{2}{*}{ Gaucher disease } & Miglustat & Substrate reduction therapy & $\begin{array}{l}\text { Osmotic diarrhea and } \\
\text { weight loss observed in the } \\
\text { majority of patients. Periph- } \\
\text { eral neuropathy and tremor } \\
\text { may occur }\end{array}$ & $\begin{array}{l}\text { Reduction of } \\
\text { glycosphingolipids, im- } \\
\text { provement in anemia and } \\
\text { thrombocytopenia. Less ef- } \\
\text { fective, in general when } \\
\text { compared to ERT and } \\
\text { eliglustat }\end{array}$ \\
\hline & Eliglustat & Substrate reduction therapy & $\begin{array}{l}\text { Head- } \\
\text { ache, arthralgia, nasopharyn } \\
\text { gitis, upper respiratory in- } \\
\text { fection, diarrhea and dizzi- } \\
\text { ness were reported. Caution } \\
\text { recommended in patients } \\
\text { with concomitant use of } \\
\text { drugs that affect CYP2D6 } \\
\text { and/or CYP3A substrate } \\
\text { metabolism }\end{array}$ & $\begin{array}{l}\text { Reduction of } \\
\text { glycosphingolipids. Im- } \\
\text { provements in platelet and } \\
\text { hemoglobin levels, spleen } \\
\text { and liver volumes and bone } \\
\text { outcomes. No therapeutic } \\
\text { effect in CYP2D6 ul- } \\
\text { tra-rapid metabolizers }\end{array}$ \\
\hline Fabry disease & Migalastat & Chaperone & $\begin{array}{l}\text { Nasopharyngitis and head- } \\
\text { ache were frequently re- } \\
\text { ported }\end{array}$ & $\begin{array}{l}\text { Decreased left ventricular } \\
\text { mass index; reduction in the } \\
\text { incidence of renal, cardiac } \\
\text { or cerebrovascular events. } \\
\text { Efficacy is restricted to pa- } \\
\text { tients with amenable muta- } \\
\text { tions }\end{array}$ \\
\hline Niemann- Pick type C & Miglustat & Substrate reduction therapy & $\begin{array}{l}\text { Osmotic diarrhea and } \\
\text { weight loss observed in the } \\
\text { majority of the patients. Pe- } \\
\text { ripheral neuropathy and } \\
\text { tremor may occur }\end{array}$ & $\begin{array}{l}\text { Improvement in horizontal } \\
\text { saccadic eye movement ve- } \\
\text { locity and stabilization of } \\
\text { ambulation, manipula- } \\
\text { tion, language and swallow- } \\
\text { ing scores }\end{array}$ \\
\hline
\end{tabular}


cysteamine disulfide, and it has been shown to delay the progression of renal and extrarenal disease with impacts on survival rates (Ariceta et al., 2017).

Migalastat is a pharmacological chaperone (PC), which acts in patients with amenable mutations by stabilizing the enzyme alpha-galactosidase and facilitating lysosomal trafficking. It has been shown to decrease the left ventricular mass index and reduce the incidence of renal, cardiac or cerebrovascular events (Hughes et al., 2017). PCs are currently being investigated in other diseases including GD and aspartylglucosaminuria (Narita et al., 2016; Banning et al., 2016).

Another promising class of small molecules for the treatment of LDs is the "stop codon read-through" drugs, which act by allowing the read-through of premature termination codons in patients with nonsense mutations. Currently, there are no approved drugs of this class, but ongoing clinical trials are evaluating their potential in MPS I, a condition where nonsense mutations are relatively common. Moreover, the potential of these drugs is being evaluated for other LDs, including aspartylglucosaminuria, MPS III, MPS VI, and Niemann-Pick type B (Gómez-Grau et al., 2015; Banning et al., 2016).

\section{Gene therapy and gene editing}

The rationale for gene therapy for LDs is similar to the rationale for ERT, namely the ability of a deficient cell to take up a lysosomal enzyme from the extracellular milieu. This means that not all cells need to be corrected, as long as the distribution of the enzyme is efficient. Therefore, LDs are considered good targets for gene therapy, despite their multisystem involvement (Gonzalez and Baldo, 2017).

In LDs, the therapeutic goal is to achieve long-term gene expression and protein production. Therefore, most studies use vectors allowing long-term expression of the transgene, focusing particularly on lentiviruses, adeno-associated viruses, or other non-viral integrative approaches, such as gene editing (Sharma et al., 2015; Beck, 2018; Schuh et al., 2018).

Adeno-associated viral vectors (AAV) are emerging as the vector of choice for in vivo gene therapy approaches, especially for diseases with neurological involvement (Giugliani et al., 2018). These viruses can transduce cells that are not going through division, and persist primarily as non-integrative episomal units, although integration has been reported (Chanda et al., 2017). Pre-clinical studies in animal models have been described for most LDs, and more recently the results from the first clinical trials using these vectors were reported. Four MPS IIIA patients were treated with intracerebral injections of $7.210^{11}$ viral genomes/patient of an AAV rh.10. The vector was safe and well tolerated, with one early-treated patient showing moderate improvement in neurological parameters (Tardieu et al., 2014).
The use of lentiviruses in most clinical studies for LDs has focused on correcting hematopoietic stem cells (HSC) and transplanting these cells to the patient (ex vivo approach). A notable accomplishment, this approach was tested by injecting modified cells carrying the Arylsulfatase $\mathrm{A}(A R S A)$ gene to prevent disease manifestations in nine patients with infantile metachromatic leukodystrophy. ARSA expression levels were restored, and eight patients (89\%) had no disease symptoms (Sessa et al., 2016).

Based on the promising results from these initial trials, new studies and approaches are currently being tested. These studies include new technologies in preclinical and clinical stages, such as genome editing (Sharma et al., 2015; Poswar et al., 2017; Schuh et al., 2018) or the use of either lentiviruses or AAV in different types of MPS and possibly other LDs (Poswar et al., 2017).

\section{Conclusions and perspectives}

Although they account for less than $1 \%$ of hereditary diseases, LDs have gained significance exceeding this proportion by concentrating a large number of successful examples of treatments for genetic conditions. Hematopoietic stem cell transplantation, enzyme replacement therapy, substrate reduction therapy, and pharmacological chaperones, are some of the approved treatment modalities that are benefiting thousands of LD patients around the world. The treatment of CNS manifestations is still a major challenge, but the administration of ERT to the brain via Trojan horses or IT/ICV, as well as gene therapy/gene editing strategies, should change this picture in the near future. Patients are usually identified after clinical suspicion, in most cases, through the identification of specific enzyme deficiencies associated with the majority of these conditions. There are a growing number of sensitive and specific biomarkers being reported that could help to screen for these conditions, support the diagnosis, and provide useful information for treatment monitoring. The development of high-throughput methods, especially based on the use of DBS, is making newborn screening feasible for several LDs. The combination of early diagnosis with effective therapies is bringing practical alternatives and hope for patients and families affected by LDs.

\section{Acknowledgments}

The authors acknowledge the financial support of CAPES, CNPq, FAPERGS, and FIPE-HCPA. Also, we want to acknowledge all the personnel who have been collaborating for the past 35 years to build and grow the Medical Genetics Service of the Hospital de Clínicas de Porto Alegre.

\section{Conflict of interest}

The authors declare no conflict of interest. 


\section{Author Contributions}

FOP, FV, MB, KMT, ACBF, FK, CFMS, and GB contributed to specific sections of the manuscript; RG conceived the study. All authors read and approved the submitted version of the manuscript.

\section{References}

Aldenhoven M, Wynn RF, Orchard PJ, O'Meara A, Veys P, Fischer A, Valayannopoulos V, Neven B, Rovelli A, Prasad VK et al. (2015) Long-term outcome of Hurler syndrome patients after hematopoietic cell transplantation: an international multicenter study. Blood 125:2164-2172.

Ariceta G, Giordano V and Santos F (2017) Effects of long-term cysteamine treatment in patients with cystinosis. Pediatr Nephrol 34:571-578.

Balwani M, Burrow TA, Charrow J, Goker-Alpan O, Kaplan P, Kishnani PS, Mistry P, Ruskin J and Weinreb N (2016) Recommendations for the use of eliglustat in the treatment of adults with Gaucher disease type 1 in the United States. Mol Genet Metab 117:95-103.

Banning A, Gülec C, Rouvinen J, Gray SJ and Tikkanen R (2016) Identification of small molecule compounds for pharmacological chaperone therapy of aspartylglucosaminuria. Sci Rep 6:37583.

Barth AL, de Magalhães TSPC, Reis ABR, de Oliveira ML, Scalco FB, Cavalcanti NC, Silva DSE, Torres DA, Costa AAP, Bonfim C et al. (2017) Early hematopoietic stem cell transplantation in a patient with severe mucopolysaccharidosis II: A 7years follow-up. Mol Genet Metab Rep $12: 62-68$

Barton NW, Brady RO, Dambrosia JM, Di Bisceglie AM, Doppelt SH, Hill SC, Mankin HJ, Murray GJ, Parker RI and Argoff CE (1991) Replacement therapy for inherited enzyme deficiency macrophage-targeted glucocerebrosidase for Gaucher's disease. N Engl J Med 324:1464-1470.

Beck M (2018) Treatment strategies for lysosomal storage disorders. Dev Med Child Neurol 60:13-18.

Behfar M, Dehghani SS, Rostami T, Ghavamzadeh A and Hamidieh AA (2017) Non-sibling hematopoietic stem cell transplantation using myeloablative conditioning regimen in children with Maroteaux-Lamy syndrome: A brief report. Pediatr Transplant 21:e12981.

Beirão I, Cabrita A, Torres M, Silva F, Aguiar P, Laranjeira F and Gomes AM (2017) Biomarkers and imaging findings of Anderson-Fabry disease-What we know now. Diseases 5:15.

Belmatoug N, Di Rocco M, Fraga C, Giraldo P, Hughes D, Lukina E, Maison-Blanche P, Merkel M, Niederau C, Plöckinger U et al. (2017) Management and monitoring recommendations for the use of eliglustat in adults with type 1 Gaucher disease in Europe. Eur J Intern Med 37:25-32.

Biegstraaten M, Arngrímsson R, Barbey F, Boks L, Cecchi F, Deegan PB, Feldt-Rasmussen U, Geberhiwot T, Germain DP, Hendriksz C et al. (2015) Recommendations for initiation and cessation of enzyme replacement therapy in patients with Fabry disease: The European Fabry Working Group consensus document. Orphanet J Rare Dis 10:36

Blau N, Duran M and Gibson KM (2008) Laboratory Guide to the Methods in Biochemical Genetics. Springer-Verlag, Heidelberg, $860 \mathrm{pp}$.
Bobillo Lobato J, Jiménez Hidalgo M and Jiménez Jiménez L (2016) Biomarkers in lysosomal storage diseases. Diseases 4:40.

Boelens JJ and van Hasselt PM (2016) Neurodevelopmental outcome after hematopoietic cell transplantation in inborn errors of Mmetabolism: Current considerations and future perspectives. Neuropediatrics 47:285-292.

Borgwardt L, Dali CI, Fogh J, Månsson JE, Olsen KJ, Beck HC, Nielsen KG, Nielsen LH, Olsen SOE, Riise Stensland HMF et al. (2013) Enzyme replacement therapy for alpha-mannosidosis: 12 months follow-up of a single centre, randomised, multiple dose study. J Inherit Metab Dis 36:1015-1024.

Boucher AA, Miller W, Shanley R, Ziegler R, Lund T, Raymond $G$ and Orchard PJ (2015) Long-term outcomes after allogeneic hematopoietic stem cell transplantation for metachromatic leukodystrophy: The largest single-institution cohort report. Orphanet J Rare Dis 10:94.

Bowman EA, Velakoulis D, Desmond P and Walterfang M (2017) Longitudinal changes in white matter fractional anisotropy in adult-onset Niemann-Pick disease type $\mathrm{C}$ patients treated with miglustat. JIMD Reports 39:39-43.

Bradbury A, Bagel J, Sampson M, Farhat N, Ding W, Swain G, Prociuk M, ODonnell P, Drobatz K, Gurda B et al. (2016) Cerebrospinal fluid Calbindin D concentration as a biomarker of cerebellar disease progression in Niemann-Pick Type C1 disease. J Pharmacol Exp Ther 358:254-261.

Brusius-Facchin AC, Schwartz IVD, Zimmer C, Ribeiro MG, Acosta AX, Horovitz D, Monlleó IL, Fontes MIB, FettConte A, Sobrinho RPO et al. (2014) Mucopolysaccharidosis type II: Identification of 30 novel mutations among Latin American patients. Mol Genet Metab 111:133-138.

Burns T (2016) Tietz Fundamentos de Química Clínica e Diagnóstico Molecular. Elsevier, Rio de Janeiro, 1106 p.

Cabrera-Salazar MA, DeRiso M, Bercury SD, Li L, Lydon JT, Weber W, Pande N, Cromwell MA, Copeland D, Leonard J et al. (2012) Systemic delivery of a glucosylceramide synthase inhibitor reduces CNS substrates and increases lifespan in a mouse model of Type 2 Gaucher disease. PLoS One 7:e43310.

Chanda D, Hensel JA, Higgs JT, Grover R, Kaza N and Ponnazhagan S (2017) Effects of cellular methylation on transgene expression and site-specific integration of adenoassociated virus. Genes 8:232.

Chinen Y, Higa T, Tomatsu S, Suzuki Y, Orii T and Hyakuna N (2014) Long-term therapeutic efficacy of allogenic bone marrow transplantation in a patient with mucopolysaccharidosis IVA. Mol Genet Metab Rep 1:31-41.

Coutinho M, Santos J, Matos L and Alves S (2016) Genetic substrate reduction therapy: A promising approach for lysosomal storage disorders. Diseases 4:33.

Derrick-Roberts A, Jackson M, Pyragius C and Byers S (2017) Substrate deprivation therapy to reduce glycosaminoglycan synthesis improves aspects of neurological and skeletal pathology in MPS I mice. Diseases 5:5

Dickson PI, Kaitila I, Harmatz P, Mlikotic A, Chen AH, Victoroff A, Passage MB, Madden J, Le SQ and Naylor DE (2015) Safety of laronidase delivered into the spinal canal for treatment of cervical stenosis in mucopolysaccharidosis I. Mol Genet Metab 116:69-74. 
Ferreira CR and Gahl WA (2017) Lysosomal storage diseases. Transl Sci Rare Dis 2:1-71.

Filocamo M and Morrone A (2011) Lysosomal storage disorders: Molecular basis and laboratory testing. Hum Genomics 5:156-169.

Giese A-K, Mascher H, Grittner U, Eichler S, Kramp G, Lukas J, te Vruchte D, Al Eisa N, Cortina-Borja M, Porter FD et al. (2015) A novel, highly sensitive and specific biomarker for Niemann-Pick type C1 disease. Orphanet J Rare Dis 10:78.

Giugliani R, Federhen A, Michelin-Tirelli K, Riegel M and Burin M (2017a) Relative frequency and estimated minimal frequency of lysosomal storage diseases in Brazil: Report from a reference laboratory. Genet Mol Biol 40:31-39.

Giugliani R, Vairo F, Beck M, Wraith E, Cowan T and Grabowski G (2017b) Lysosomal disorders. In: Sarafoglou K, Hoffmann GF and Roth KS (eds) Pediatric Endocrinology and Inborn Errors of Metabolism, 2nd edition. McGraw-Hill Education, New York, pp 983-1021.

Giugliani R, Vairo F, Kubaski F, Poswar F, Riegel M, Baldo G and Saute JA (2018) Neurological manifestations of lysosomal disorders and emerging therapies targeting the CNS. Lancet Child Adolesc Health 2:56-68.

Gómez-Grau M, Garrido E, Cozar M, Rodriguez-Sureda V, Domínguez C, Arenas C, Gatti RA, Cormand B, Grinberg D and Vilageliu L (2015) Evaluation of aminoglycoside and non-aminoglycoside compounds for stop-codon readthrough therapy in four lysosomal storage diseases. PLoS One 10:e0135873.

Gonzalez EA and Baldo G (2017) Gene therapy for lysosomal storage disorders: Recent advances and limitations. J Inborn Errors Metab Screen 5:1-6.

Hammerschmidt TG, de Oliveira Schmitt Ribas G, SaraivaPereira ML, Bonatto MP, Kessler RG, Souza FTS, Trapp F, Michelin-Tirelli K, Burin MG, Giugliani R et al. (2018) Molecular and biochemical biomarkers for diagnosis and therapy monitorization of Niemann-Pick type $\mathrm{C}$ patients. Int $\mathrm{J}$ Dev Neurosci 66:18-23.

Henry JB and Gubert IC (2008) Diagnósticos Clínicos e Tratamento por Métodos Laboratoriais. Manole, Barueri, $1664 \mathrm{p}$.

Hughes DA, Nicholls K, Shankar SP, Sunder-Plassmann G, Koeller D, Nedd K, Vockley G, Hamazaki T, Lachmann R, Ohashi $\mathrm{T}$ et al. (2017) Oral pharmacological chaperone migalastat compared with enzyme replacement therapy in Fabry disease: 18-month results from the randomised phase III ATTRACT study. J Med Genet 54:288-296.

Jiang M, Liu S, Jiang H, Lin Y, Shao Y, Hu H, Zhao X, Liu H, Huang Y and Liu L (2017) Brain abnormalities in fucosidosis: Transplantation or supportive therapy? Metab Brain Dis $32: 317-320$

Jurecka A and Tylki-Szymanska A (2015) Enzyme replacement therapy: Lessons learned and emerging questions. Expert Opin Orphan Drugs 3:293-305.

Kingma SDK, Bodamer OA and Wijburg FA (2015) Epidemiology and diagnosis of lysosomal storage disorders; challenges of screening. Best Pract Res Clin Endocrinol Metab 29:145-157.

Kishnani P, Tarnopolsky M, Roberts M, Sivakumar K, Dasouki M, Dimachkie MM, Finanger E, Goker-Alpan O, Guter KA, Mozaffar T et al. (2017) Duvoglustat $\mathrm{HCl}$ increases systemic and tissue exposure of active acid $\alpha$-glucosidase in
Pompe patients co-administered with alglucosidase $\alpha$. Mol Ther 25:1199-1208.

Kornfeld S (1992) Structure and function of the mannose 6-phosphate/insulin like growth factor II receptors. Annu Rev Biochem 61:307-330.

Kubaski F, Osago H, Mason RW, Yamaguchi S, Kobayashi H, Tsuchiya M, Orii T and Tomatsu S (2017) Glycosaminoglycans detection methods: Applications of mass spectrometry. Mol Genet Metab 120:67-77.

Langan TJ, Barcykowski AL, Dare J, Pannullo EC, Muscarella L and Carter RL (2016) Evidence for improved survival in postsymptomatic stem cell-transplanted patients with Krabbe's disease: Transplantation for symptomatic Krabbe's disease. J Neurosci Res 94:1189-1194.

Langereis EJ, Wagemans T, Kulik W, Lefeber DJ, van Lenthe H, Oussoren E, van der Ploeg AT, Ruijter GJ, Wevers RA, Wijburg FA et al. (2015) A multiplex assay for the diagnosis of mucopolysaccharidoses and mucolipidoses. PLoS One 10: e0138622.

Lloyd-Evans E and Haslett LJ (2016) The lysosomal storage disease continuum with ageing-related neurodegenerative disease. Ageing Res Rev 32:104-121.

Lum SH, Stepien KM, Ghosh A, Broomfield A, Church H, Mercer J, Jones S and Wynn R (2017) Long-term survival and cardiopulmonary outcome in children with Hurler syndrome after haematopoietic stem cell transplantation. J Inherit Metab Dis 40:455-460.

Lund TC (2013) Hematopoietic stem cell transplant for lysosomal storage diseases. Pediatr Endocrinol Rev 11 Suppl 1:91-98.

Lyseng-Williamson KA (2014) Miglustat: A review of its use in Niemann-Pick disease type C. Drugs 74:61-74.

Macauley SL (2016) Combination therapies for lysosomal storage diseases: A complex answer to a simple problem. Pediatr Endocrinol Rev 13 Suppl 1:639-648.

Maher KR and Yeager AM (2016) Cellular transplant therapies for globoid cell leukodystrophy: Preclinical and clinical observations: Cellular therapy for GLD. J Neurosci Res 94:1180-1188.

Manwaring V, Prunty H, Bainbridge K, Burke D, Finnegan N, Franses R, Lam A, Vellodi A and Heales S (2012) Urine analysis of glucose tetrasaccharide by HPLC; a useful marker for the investigation of patients with Pompe and other glycogen storage diseases. J Inherit Metab Dis 35:311-316.

Mikulka CR and Sands MS (2016) Treatment for Krabbe's disease: Finding the combination. J Neurosci Res 94:1126-1137.

Montaño AM, Lock-Hock N, Steiner RD, Graham BH, Szlago M, Greenstein R, Pineda M, Gonzalez-Meneses A, Çoker M, Bartholomew D et al. (2016) Clinical course of Sly syndrome (Mucopolysaccharidosis Type VII). J Med Genet 53:403-418.

Muenzer J, Hendriksz CJ, Fan Z, Vijayaraghavan S, Perry V, Santra S, Solanki GA, Mascelli MA, Pan L, Wang N et al. (2016) A phase I/II study of intrathecal idursulfase-IT in children with severe mucopolysaccharidosis II. Genet Med 18:73-81.

Munoz-Rojas MV, Vieira T, Costa R, Fagondes S, John A, Jardim LB, Vedolin LM, Raymundo M, Dickson PI, Kakkis E et al. (2008) Intrathecal enzyme replacement therapy in a patient with mucopolysaccharidosis type I and symptomatic spinal cord compression. Am J Med Genet A 146A:2538-2544. 
Muschol N, Cleary M, Couce ML, Shaywitz AJ, Cahan H, Grover A, Maricich SM, Melton A, Smith L and de Castro Lopez MJ (2018) ICV-administered BMN 250 (NAGLU-IGF2) is well tolerated and reduces heparan sulfate accumulation in the CNS of subjects with Sanfilippo syndrome type B (MPS IIIB). Mol Genet Metab 123:S102.

Narita A, Shirai K, Itamura S, Matsuda A, Ishihara A, Matsushita K, Fukuda C, Kubota N, Takayama R, Shigematsu H et al. (2016) Ambroxol chaperone therapy for neuronopathic Gaucher disease: A pilot study. Ann Clin Transl Neurol 3:200-215.

Nelson DL and Cox MM (2014) Princípios de bioquímica de Lehninger. Artmed, Porto Alegre, 1328 p.

Neufeld EF and Fratantoni JC (1970) Inborn errors of mucopolysaccharide metabolism: Faulty degradative mechanisms are implicated in this group of human diseases. Science 169:141-146.

Nowak A, Mechtler T, Kasper DC and Desnick RJ (2017a) Correlation of Lyso-Gb3 levels in dried blood spots and sera from patients with classic and Later-Onset Fabry disease. Mol Genet Metab 121:320-324.

Nowak A, Mechtler TP, Desnick RJ and Kasper DC (2017b) Plasma LysoGb3: A useful biomarker for the diagnosis and treatment of Fabry disease heterozygotes. Mol Genet Metab 120:57-61.

Ortolano S, Viéitez I, Navarro C and Spuch C (2014) Treatment of lysosomal storage diseases: Recent patents and future strategies. Recent Pat Endocr Metab Immune Drug Discov 8:9-25.

Pardridge WM, Boado RJ, Giugliani R and Schmidt M (2018) Plasma pharmacokinetics of valanafusp alpha, a human insulin receptor antibody-iduronidase fusion protein, in patients with mucopolysaccharidosis type I. BioDrugs 32:169-176.

Parini R, Deodato F, Di Rocco M, Lanino E, Locatelli F, Messina C, Rovelli A and Scarpa M (2017) Open issues in mucopolysaccharidosis type I-Hurler. Orphanet J Rare Dis 12:112.

Poretti A, Meoded A and Fatemi A (2016) Diffusion tensor imaging: A biomarker of outcome in Krabbe's disease. J Neurosci Res 94:1108-1115.

Poswar F, Baldo G and Giugliani R (2017) Phase I and II clinical trials for the mucopolysaccharidoses. Expert Opin Investig Drugs 26:1331-1340.

Rastall DPW and Amalfitano A (2017) Current and future treatments for lysosomal storage disorders. Curr Treat Options Neurol 19:45.

Raymond K and Rinaldo P (2013) From art to science: Oligosaccharide analysis by MALDI-TOF mass spectrometry finally replaces 1-dimensional thin-layer chromatography. Clin Chem 59:1297-1298.

Rolfs A, Giese A-K, Grittner U, Mascher D, Elstein D, Zimran A, Böttcher T, Lukas J, Hübner R, Gölnitz U et al. (2013) Glucosylsphingosine is a highly sensitive and specific biomarker for primary diagnostic and follow-up monitoring in Gaucher disease in a Non-Jewish, Caucasian cohort of Gaucher disease patients. PLoS One 8:e79732.

Sabatini DD and Adesnik MB (2014) The biogenesis of membranes and organelles. In: Beaudet AL, Vogelstein B, Kinzler $\mathrm{KW}$, Antonarakis SE, Ballabio A, Gibson KM and
Mitchell G (eds) The Online Metabolic and Molecular Bases of Inherited Disease. McGraw-Hill, New York.

Sands SA and LeVine SM (2016) Substrate reduction therapy for Krabbe's disease. J Neurosci Res 94:1261-1272.

Schielen P, Kemper E and Gelb M (2017) Newborn screening for lysosomal storage diseases: A concise review of the literature on screening methods, therapeutic possibilities and regional programs. Int J Neonatal Screen 3:6.

Schuh RS, de Carvalho TG, Giugliani R, Matte U, Baldo G and Teixeira HF (2018) Gene editing of MPS I human fibroblasts by co-delivery of a CRISPR/Cas9 plasmid and a donor oligonucleotide using nanoemulsions as nonviral carriers. Eur J Pharm Biopharm 122:158-166.

Sessa M, Lorioli L, Fumagalli F, Acquati S, Redaelli D, Baldoli C, Canale S, Lopez ID, Morena F, Calabria A et al. (2016) Lentiviral haemopoietic stem-cell gene therapy in early-onset metachromatic leukodystrophy: An ad hoc analysis of a non-randomised, open-label, Phase 1/2 trial. Lancet 388:476-487.

Sharma R, Anguela XM, Doyon Y, Wechsler T, DeKelver RC, Sproul S, Paschon DE, Miller JC, Davidson RJ, Shivak D et al. (2015) In vivo genome editing of the albumin locus as a platform for protein replacement therapy. Blood 126:1777-1784.

Tardieu M, Zérah M, Husson B, de Bournonville S, Deiva K, Adamsbaum C, Vincent F, Hocquemiller M, Broissand C, Furlan V et al. (2014) Intracerebral administration of adeno-associated viral vector serotype rh.10 carrying human SGSH and SUMF1 cDNAs in children with mucopolysaccharidosis type IIIA disease: Results of a Phase I/II trial. Hum Gene Ther 25:506-516.

Tortelli B, Fujiwara H, Bagel JH, Zhang J, Sidhu R, Jiang X, Yanjanin NM, Shankar RK, Carillo-Carasco N, Heiss J et al. (2014) Cholesterol homeostatic responses provide biomarkers for monitoring treatment for the neurodegenerative disease Niemann-Pick C1 (NPC1). Hum Mol Genet 23:6022-6033.

Turgeon CT, Magera MJ, Cuthbert CD, Loken PR, Gavrilov DK, Tortorelli S, Raymond KM, Oglesbee D, Rinaldo P and Matern D (2010) Determination of total homocysteine, methylmalonic acid, and 2-methylcitric acid in dried blood spots by tandem mass spectrometry. Clin Chem 56:16861695.

Vairo F, Sperb-Ludwig F, Wilke M, Michellin-Tirelli K, Netto C, Neto EC and Schwartz I (2015) Osteopontin: A potential biomarker of Gaucher disease. Ann Hematol 94:1119-1125.

Vairo FP, Boczek NJ, Cousin MA, Kaiwar C, Blackburn PR, Conboy E, Lanpher BC, Gavrilova RH, Pichurin PN, Lazaridis $\mathrm{KN}$ et al. (2017) The prevalence of diseases caused by lysosome-related genes in a cohort of undiagnosed patients. Mol Genet Metab Rep 13:46-51.

Valle D, Beaudet AL, Vogelstein B, Kinzler KW, Antonarakis SE, Ballabio A, Gibson K and Mitchell G (2014) The Online Metabolic and Molecular Bases of Inherited Disease. McGraw-Hill, New York.

van Breemen MJ, de Fost M, Voerman JSA, Laman JD, Boot RG, Maas M, Hollak CEM, Aerts JM and Rezaee F (2007) Increased plasma macrophage inflammatory protein (MIP)- $1 \alpha$ and MIP-1 $\beta$ levels in type 1 Gaucher disease. Biochim Biophys Acta Mol Basis Dis 1772:788-796. 
van Gelder CM, Hoogeveen-Westerveld M, Kroos MA, Plug I, van der Ploeg AT and Reuser AJJ (2015) Enzyme therapy and immune response in relation to CRIM status: The Dutch experience in classic infantile Pompe disease. J Inherit Metab Dis 38:305-314.

Wasserstein MP, Diaz GA, Lachmann RH, Jouvin M-H, Nandy I, Ji AJ and Puga AC (2018) Olipudase alpha for treatment of acid sphingomyelinase deficiency (ASMD): Safety and efficacy in adults treated for 30 months. J Inherit Metab Dis 41:829-838.

Wright MD, Poe MD, DeRenzo A, Haldal S and Escolar ML (2017) Developmental outcomes of cord blood transplantation for Krabbe disease: A 15-year study. Neurology 89:1365-1372.

Yabe H, Tanaka A, Chinen Y, Kato S, Sawamoto K, Yasuda E, Shintaku H, Suzuki Y, Orii T and Tomatsu S (2016) Hematopoietic stem cell transplantation for Morquio A syndrome. Mol Genet Metab 117:84-94

Yamada Y, Kato K, Sukegawa K, Tomatsu S, Fukuda S, Emura S, Kojima S, Matsuyama T, Sly W, Kondo N et al. (1998) Treatment of MPS VII (Sly disease) by allogeneic BMT in a female with homozygous A619V mutation. Bone Marrow Transplant 21:629-634.

Young SP, Zhang H, Corzo D, Thurberg BL, Bali D, Kishnani PS and Millington DS (2009) Long-term monitoring of patients with infantile-onset Pompe disease on enzyme replacement therapy using a urinary glucose tetrasaccharide biomarker. Genet Med 11:536-541.

Zimran A, Goldblatt J and Szer J (2018) Should eliglustat be first line therapy for patients with type 1 Gaucher disease? Definitions of safety and efficacy. Blood Cells Mol Dis 68:14-16.

\section{Internet resources}

WORLDSymposium (2018) Official List of Lysosomal Diseases, https://www.worldsymposia.org/offi-

cial-list-of-lysosomal-diseases (accessed 9 January 2018).

Associate Editor: Mariluce Riegel

License information: This is an open-access article distributed under the terms of the Creative Commons Attribution License (type CC-BY), which permits unrestricted use, distribution and reproduction in any medium, provided the original article is properly cited. 